\section{Articulação da indústria farmacêutica brasileira com o exterior: há evidências de especialização regressiva?}

\author{
The Brazilian pharmaceutical industry and \\ foreign trade: is there evidence of \\ regressive specialization?
}

\author{
1 Instituto de Economia, \\ Universidade Federal do Rio \\ de Janeiro, Rio de Janeiro, \\ Brasil. \\ 2 Escola Nacional de Saúde \\ Pública Sergio Arouca, \\ Fundação Oswaldo Cruz, \\ Rio de Janeiro, Brasil. \\ Correspondência \\ F. B. Mota \\ Instituto de Economia \\ Universidade Federal do Rio \\ de Janeiro. \\ Av. Pasteur 250, sala 104, \\ Rio de Janeiro, $R J$ \\ 22290-240, Brasil. \\ motafb@hotmail.com
}

\begin{abstract}
Based on an exploratory discussion, the aim of this article is to investigate whether there is evidence of regressive specialization in the foreign trade pattern of the Brazilian pharmaceutical industry since trade liberalization in the 1990s. A descriptive statistical analysis drew on data for foreign trade in pharmaceutical and organic chemical products, available in the Aliceweb system of the Ministry of Development, Industry, and Foreign Trade, covering the periods 1989-1995 and 1996-2008. The results, especially concerning trends in Brazil's trade with developed countries, suggest evidence of regressive specialization.
\end{abstract}

Drug Industry; Pharmaceutical Trade; Commerce
Fábio Batista Mota 1 José Eduardo Cassiolato 1 Carlos Augusto Grabois Gadelha 2

\section{Introdução}

Em caráter exploratório, o presente artigo tem por objetivo investigar se há indícios de especialização regressiva no padrão de comércio exterior da indústria farmacêutica brasileira, a partir da liberalização comercial dos anos 1990. Assim, considerada a necessidade de estabelecimento de um quadro analítico que delimite as "fronteiras" do estudo, serão observados, apenas, os aspectos relacionados à articulação de tal indústria com o exterior, pós-liberalização comercial. Esse corte empírico encontra justificativa no fato de que, segundo Katz ${ }^{1}$ e CEPAL 2 , firmas que atuam em setores industriais baseados em ciência, como o farmacêutico, após a redução da proteção tarifária no período pós-reformas, passaram a se articular mais com o exterior do que com o doméstico, isto é, intensificaram a importação de bens de capital e insumos intermediários de suas respectivas matrizes (comércio internacional intrafirma), em detrimento da fabricação local. Assertiva semelhante pode ser encontrada, também, em Kupfer 3 e Gadelha 4.

Como sabido, usualmente se admite o ano 1990 como divisor dos períodos pré e pós-reformas liberalizantes. Porém, analiticamente, há uma limitação metodológica na utilização desse ano como referência, quando da análise do comércio exterior, visto que, a partir de janeiro de 1996, o Brasil passou a adotar - em substituição à Nomenclatura Brasileira de Mercadorias (NBM), 
que vigorou de janeiro de 1989 a dezembro de 1995 - a Nomenclatura Comum do Mercosul (NCM), a atual base de classificação das estatísticas de comércio exterior no Brasil (adequando-se ao padrão internacional, o Sistema Harmonizado de Designação e Codificação de Mercadorias). A despeito da existência de uma tabela de correlação de códigos de mercadorias entre a NCM e a NBM, disponibilizada pelo Ministério do Desenvolvimento, Indústria e Comércio Exterior, apenas um terço, aproximadamente, dos códigos NCM/NBM tem correlação direta entre si. Assim, de modo a evitar as dificuldades relacionadas à conversão da NBM em NCM, a análise temporal do comércio exterior aqui realizada admitiu uma descontinuidade na série dos dados a partir de janeiro de 1996.

Realizou-se, aqui, uma análise estatística descritiva abrangendo o período de janeiro de 1989 a dezembro de 1995 e janeiro de 1996 a dezembro de 2008. Dada a mudança da NBM para a NCM, tais períodos não são diretamente comparáveis. Portanto, especial atenção será dada ao período 1996-2008. Para proceder à investigação, foram utilizados dados secundários de exportação/importação de "produtos farmacêuticos" e "produtos químicos orgânicos" - respectivamente, capítulos 30 e 29 da $\mathrm{NCM}^{5}$-, disponíveis no Sistema de Análise das Informações de Comércio Exterior via Internet (ALICEweb) 6 , do Ministério do Desenvolvimento, Indústria e Comércio Exterior. O método aqui proposto tem por base, em parte, Gadelha 4, que investigou a situação de dependência do comércio exterior no âmbito do Complexo Econômico Industrial da Saúde (CEIS).

Seguem algumas considerações de ordem metodológica e suas implicações para os resultados do estudo. Os dados de comércio exterior do sistema ALICEweb (exportação/importação/saldo/corrente de comércio) são disponibilizados de forma agregada (valores US\$ Free on Board (FOB) por ano/período consultado, para dado capítulo da NCM, ou intervalo de capítulos) e, também, de forma detalhada. A última opção, porém, discrimina valores para cada item da NCM, gerando um número bastante elevado de observações (por código NCM/descrição NCM) - por exemplo, para apenas um nível de detalhamento, a consulta das importações brasileiras referentes aos capítulos 29 e 30 da NCM, em conjunto, para o período janeiro de 1996 a dezembro de 2008, retorna um total de 2.108 observações. Logo, para fins de simplificação da análise, dado tratar-se de um estudo exploratório, foram utilizados dados agregados de comércio exterior. Tal aspecto constitui uma limitação metodológica ao estudo, implicando certa superestimação dos resultados. Isso especialmente para o Capítulo 29, uma vez que inclui, também, itens de produtos que são importados/exportados por outros "setores", além da indústria farmacêutica. Todavia, conforme argumenta Gadelha 4, ainda que persistam tais "problemas", que são inerentes ao padrão de classificação da NCM, a análise de valores agregados constitui um bom indicador do desempenho do segmento de fármacos.

Este artigo está estruturado em mais duas seções, além desta introdutória e das considerações finais. A segunda seção apresenta, muito brevemente, uma visão geral das reformas estruturais pró-competitivas implementadas na América Latina e Brasil, sobretudo no que tange à liberalização comercial. A terceira seção apresenta os resultados do estudo.

\section{Reformas estruturais pró-competitivas: uma visão geral}

O objetivo desta seção é apresentar, brevemente, um panorama geral acerca das reformas estruturais pró-competitivas ocorridas na América Latina (a partir dos anos 1970, Chile) e Brasil (iniciadas nos anos 1990), no bojo da disseminação das diretrizes do Consenso de Washington. Em boa parte, os textos aqui trabalhados têm por base teórica a abordagem neo-schumpeteriana da firma, que abarca, também, trabalhos mais recentes da CEPAL. Para uma discussão mais ampla sobre esta temática no Brasil, vide, por exemplo, Kupfer 3,7, e, na America Latina, Katz 1; CEPAL 2; Cimoli \& Katz 8 .

De forma geral, desde os anos 1970 a América Latina vem introduzindo reformas estruturais de mercado, intensificadas, em boa parte dos países, nos anos 1990, como no caso do Brasil. As chamadas reformas estruturais pró-competitivas consistem, grosso modo, na abertura da economia à concorrência externa (liberalização comercial), desregulação dos diversos mercados e privatização de atividades econômicas 1,2,3,7,9. A aplicação dessas reformas exigiu dos países latino-americanos a transição de um regime orientado, de forma geral, de dentro e liderado pelo Estado, para outro mais aberto e desregulado. Tais políticas, no bojo da intensificação, nos anos 1990, do processo de globalização da economia mundial, resultaram em profundas modificações no aparato político, econômico, institucional e tecnológico dos diversos países da América Latina, em diferentes níveis; contudo com resultados muito aquém do esperado. Nessa linha de pensamento, a consequência da adoção, acrítica, das ideias do Consenso de Washington na América Latina foi um quadro no qual a maior parte 
dos seus países ainda carece de uma estratégia de crescimento de longo prazo capaz de alcançar, ao mesmo tempo, menor volatilidade macroeconômica e maiores taxas de expansão da economia, competitividade internacional, desempenho inovador e tecnológico, tanto como maiores níveis de equidade ${ }^{9}$.

Em geral, na America Latina, as reformas estruturais pró-competitivas dos anos 1990 deram origem a um episódio de longo prazo de um processo de destruição criativa schumpeteriano, no qual se deu a transição de um paradigma de desenvolvimento "endodirigido", liderado pelo Estado (especialmente a industrialização por substituição de importações; caso do Brasil) para outro mais aberto e desregulado, chamado "Novo Modelo Econômico Latino-Americano"; lastreado em recomendações normativas (Consenso de Washington) originárias da teoria neoclássica, o atual mainstream econômico 1,2. Esse novo ambiente, mais aberto e desregulado, implicou, do ponto de vista micro, profundas transformações na conduta e tomada de decisão dos agentes econômicos, particularmente as firmas 8 .

Consequentemente, no plano microeconômico, tais reformas originaram novos padrões de especialização produtiva e de inserção nos mercados mundiais de bens e serviços que resultaram na diminuição do grau de integração vertical das firmas, na medida em que os distintos regimes tecnológicos e competitivos setoriais passaram a se articular mais com o exterior do que com o doméstico. Vale dizer, com as chamadas reformas estruturais pró-competitivas, iniciaram-se novos padrões de comportamento microeconômico que privilegiaram a importação de bens de capital e insumos intermediários, em detrimento da produção doméstica e dos esforços tecnológicos associados à sua fabricação 1,2. No Brasil, aparentemente, esse fenômeno é mais conhecido pelo nome "especialização regressiva", no comércio exterior - refere-se à elevação da participação das importações de produtos de maior sofisticação tecnológica, acompanhada da exportação de produtos mais simples, em termos do seu conteúdo tecnológico ${ }^{3}$. Tal argumento pode ser encontrado, também, em Gadelha 4; ainda que não faça uso desse conceito.

Dentre as evidências empíricas que ilustram o processo de transformação pelo qual passaram os distintos regimes tecnológicos e competitivos setoriais da América Latina nos anos 1990 - que resultou no Novo Modelo Econômico LatinoAmericano -, podem-se citar: (a) "morte" e "nascimento" de firmas - com incorporação de novas tecnologias de produto, processo e organização do trabalho mais próximos da fronteira tecnológica; (b) "rejuvenescimento" do parque de maquinaria e equipamentos e deslocamento da engenharia nacional - consequência do barateamento dos bens de capital importados, resultado da abertura comercial; (c) reestruturação institucional - como harmonização do quadro institucional doméstico com o de países desenvolvidos; (d) e nova articulação com o exterior - onde os distintos regimes tecnológicos e competitivos setoriais passam a se articular mais com o exterior do que com o doméstico 1,2.

Na América Latina, os setores que mais sofreram devido à liberalização comercial e à desregulação dos mercados foram, por um lado, aqueles produtores de bens e serviços intensivos em conhecimento, e, por outro, aqueles intensivos em trabalho, produtores de bens de consumo não duráveis. Os primeiros, por conta da competição externa de firmas de países desenvolvidos, fornecedoras de produtos tecnologicamente mais avançados, na fronteira do conhecimento. Os últimos, pela concorrência de produtos originários de países como China, notadamente, e Vietnã, intensivos em mão-de-obra muito barata; inclusive frente aos países da América Latina. Por outro lado, os setores que mais avançaram foram aqueles: produtores de serviços considerados não comercializáveis internacionalmente (non tradable); baseados em recursos naturais (produtores de commodities); que operam sob o regime de maquila, produtores de equipamentos eletrônicos, usualmente para exportação; e o automobilístico ${ }^{8}$.

Como resultado, ao longo do tempo, foram se consolidando severas mudanças no padrão de especialização produtiva e inserção no comércio internacional. Porém, no conjunto dos países da América Latina, dois grandes modelos de produção especializada são considerados, atualmente, dominantes: o modelo "baseado em recursos naturais" e o de "maquila", ambos fortemente orientados para o mercado externo. O primeiro - mais encontrado na Argentina, Brasil, Chile e Uruguai -, capital intensivo, tem se mostrado, na produção de commodities, bastante competitivo no comércio internacional. O segundo - centrado no México e vários outros países da América central -, trabalho intensivo, porém barato e pouco qualificado, emprega tecnologias just-in-time, técnicas de qualidade total, Kanban e logísticas sofisticadas de produção. Firmas que operam segundo o modelo de maquila, atuam, usualmente, como montadoras de peças e componentes eletrônicos importados e na exportação do produto acabado 1,2,8.

Em ambos os modelos, interações micro-macro, assim como o citado processo de destruição criativa schumpeteriano, assumiram, na América Latina, um papel crucial para a entrada/saída 
de firmas e sua adaptação ao novo regime global de incentivos; incluindo-se, aí, as transformações na especialização produtiva e no padrão de inserção externa. Com a liberalização comercial, o que se viu foi uma redução significativa do preço dos bens de capital e insumos importados - de maior conteúdo tecnológico -, induzindo a sua escolha frente àqueles produzidos localmente e, consequentemente, o deslocamento da produção e dos esforços tecnológicos associados à sua fabricação ${ }^{8}$. Em resumo, após a liberalização comercial e a desregulação dos mercados, o resultado foi não apenas o agravamento do hiato tecnológico frente aos países mais desenvolvidos (maduros industrialmente), mas, também, da tendência à especialização industrial e inserção externa baseada tanto em recursos naturais, produção de commodities, quanto no regime de maquila, montagem de peça e componentes importados.

No Brasil, no bojo das reformas estruturais pró-competitivas, a indústria enfrentou dois choques consecutivos no ambiente competitivo, a saber, a liberalização econômica a partir de 1990 - mas, sobretudo, a comercial - e a estabilização monetária de 1994. Ambos os choques inauguram um período de grandes transformações na indústria brasileira 7,10; adicionalmente, no Brasil, poder-se-ia sugerir um terceiro choque no ambiente competitivo, a adoção, a partir de janeiro de 1999, do regime de câmbio flutuante (de julho de 1994, implantação do Plano Real, até janeiro de 1999 vigorou o regime de câmbio fixo). Em síntese, tais reformas tiveram por objetivo a desregulação econômica, a liberalização do setor externo e a privatização da indústria (desestatização). As dimensões mais relevantes da reestruturação industrial brasileira, a partir dos anos 1980, são: o aumento da produção industrial com redução do emprego; a manutenção da estrutura produtiva, mas com nova estrutura da propriedade do capital; a tendência de especialização regressiva no padrão de comércio exterior; e a retração dos investimentos em capital fixo e Pesquisa \& Desenvolvimento ${ }^{3}$.

As reformas liberalizantes suscitaram, no Brasil, intensos debates quanto ao problema, suposto, da desindustrialização. Nos anos 1990, argumentava-se que a liberalização comercial teria provocado uma acentuada reprimarização da pauta brasileira de exportações. Mais recentemente, a desindustrialização teria decorrido via "nova doença holandesa", consequência da passagem do paradigma endodirigido e liderado pelo Estado (modelo de substituição de importações) para outro mais aberto e desregulado (segundo diretrizes do Consenso de Washington). Nessa perspectiva, as reformas liberalizantes teriam resultado não apenas em perda relativa da participação da indústria no produto interno bruto (PIB), mas principalmente no retorno a um padrão de especialização produtiva baseado em recursos naturais, orientado ao exterior 11; essa visão é consoante com os argumentos de Katz 1; CEPAL 2; Cimoli \& Katz ${ }^{8}$. A partir de 2004, a referida tendência à desindustrialização teria sido reforçada, ainda, pela combinação de baixas taxas de câmbio real - argumento, de certa forma, presente também em Gadelha 4 , mas para o caso particular do Complexo Econômico Industrial da Saúde - com o aumento dos preços relativos das principais commodities exportadas pelo país (em parte, devido ao chamado "efeito China"). Todavia, a literatura disponível não é conclusiva com relação ao problema da desindustrialização no Brasil no período pós-liberalização comercial 11.

\section{Resultados}

Os períodos 1989-1995 (janeiro de 1989 é o período inicial da série disponibilizada pelo sistema ALICEweb) e 1996-2008 não são diretamente comparáveis, em função, como explicitado, da mudança da NBM para a NCM, com, apenas, aproximadamente um terço dos códigos NCM/ NBM com correlação direta entre si. Em outras palavras, os itens de produtos pertencentes aos capítulos 29 e 30 da NBM, aqui tratados, não são necessariamente os mesmos da NCM. Assim, foi realizado um corte temporal, no qual o período que se inicia em janeiro de 1996 segue a NCM (conforme padrão do sistema ALICEweb). Logicamente, os dois períodos são analisados levando-se em conta a descontinuidade da série e comparados apenas a título de ilustração. As ilustrações ora apresentadas indicam sempre tal corte temporal. Doravante, os períodos 1989-1995 e 1996-2008 serão chamados, respectivamente, de períodos I e II.

A Tabela 1 apresenta a balança comercial da indústria farmacêutica brasileira, correspondendo ao somatório dos itens que compõem os capítulos 29 (produtos químicos orgânicos) e 30 (produtos farmacêuticos) da NBM/NCM. No que tange ao período II, observa-se, claramente, uma piora na evolução das contas externas, com o deficit comercial passando de, aproximadamente, US $\$ 2,9$ bilhões em 1996 - valores correntes US\$ free on board - para US\$ 8,9 bilhões em 2008, ou um aumento de $207,8 \%$. O mesmo raciocínio se aplica ao período I, no qual, entre 1989 e 1995, o déficit comercial nas contas externas da indústria farmacêutica foi ainda mais acentuado, apresentando um crescimento de 338,7\%. Após a liberalização econômica, particularmente a 
Brasil: evolução da balança comercial da indústria farmacêutica - valores correntes US\$ free on board.

\begin{tabular}{|c|c|c|c|c|}
\hline Ano & Exportação (X) & Importação (M) & Saldo & Corrente de comércio \\
\hline \multicolumn{5}{|c|}{$1989-1995$ * } \\
\hline 1989 & 829.308 .220 & 1.376 .263 .934 & -546.955 .714 & 2.205 .572 .154 \\
\hline 1990 & 786.464 .540 & 1.484 .056 .271 & -697.591 .731 & 2.270 .520 .811 \\
\hline 1991 & 782.967 .019 & 1.638 .654 .769 & -855.687 .750 & 2.421 .621 .788 \\
\hline 1992 & 817.189 .628 & 1.552 .082 .180 & -734.892 .552 & 2.369 .271 .808 \\
\hline 1993 & 811.905 .490 & 1.939 .599 .889 & -1.127 .694 .399 & 2.751 .505 .379 \\
\hline 1994 & 918.425 .071 & 2.616 .219 .518 & -1.697 .794 .447 & 3.534 .644 .589 \\
\hline 1995 & 1.119 .911 .668 & 3.519 .415 .556 & -2.399 .503 .888 & 4.639 .327 .224 \\
\hline \multicolumn{5}{|c|}{$1996-2008$ ** } \\
\hline 1996 & 1.146 .180 .215 & 4.037 .657 .048 & -2.891 .476 .833 & 5.183 .837 .263 \\
\hline 1997 & 1.312 .409 .962 & 4.443.198.779 & -3.130 .788 .817 & 5.755 .608 .741 \\
\hline 1998 & 1.261 .665 .964 & 4.658 .519 .842 & -3.396 .853 .878 & 5.920 .185 .806 \\
\hline 1999 & 1.222 .892 .347 & 4.778 .454 .312 & -3.555 .561 .965 & 6.001 .346 .659 \\
\hline 2000 & 1.398 .812 .955 & 4.698 .350 .873 & -3.299 .537 .918 & 6.097 .163 .828 \\
\hline 2001 & 1.150 .911 .725 & 4.888 .746 .439 & -3.737 .834 .714 & 6.039 .658 .164 \\
\hline 2002 & 1.356 .234 .885 & 4.490 .760 .881 & -3.134 .525 .996 & 5.846 .995 .766 \\
\hline 2003 & 1.586 .261 .022 & 4.618 .593 .240 & -3.032 .332 .218 & 6.204 .854 .262 \\
\hline 2004 & 1.895 .153 .569 & 5.858 .903 .621 & -3.963 .750 .052 & 7.754 .057 .190 \\
\hline 2005 & 2.391 .405 .613 & 6.374 .982 .402 & -3.983 .576 .789 & 8.766 .388 .015 \\
\hline 2006 & 2.738 .497 .404 & 7.409 .988 .440 & -4.671 .491 .036 & 10.148 .485 .844 \\
\hline 2007 & 3.407 .053 .515 & 9.892 .830 .434 & -6.485 .776 .919 & 13.299 .883 .949 \\
\hline 2008 & 3.792 .089 .236 & 12.692 .256 .724 & -8.900 .167 .488 & 16.484 .345 .960 \\
\hline
\end{tabular}

Fonte: elaboração própria a partir dos dados do sistema ALICEweb.

* Mercadoria Nomenclatura Brasileira de Mercadoria (total: capítulo 30 [produtos farmacêuticos] + capítulo 29

[produtos químicos orgânicos]);

** Mercadoria Nomenclatura Comum do Mercosul (total: capítulo 30 [produtos farmacêuticos] + capitulo 29

[produtos químicos orgânicos]).

comercial, em 1990, e a estabilização monetária, com o Plano Real em 1994 - correspondendo aos dois grandes choques que sofreu a economia brasileira nos anos 19907 - o que se verificou foi, portanto, uma maior articulação da indústria com o exterior. Porém, acentuadamente, com maior peso das importações. No acumulado do período I (exclusive 1989), de uma corrente de comércio de cerca de US\$18,0 bilhões, aproximadamente US $\$ 12,8$ bilhões eram importações, ou $70,9 \%$. No acumulado do período II, o peso das importações na corrente de comércio foi ainda mais forte. De uma corrente de comércio de aproximadamente US\$103,5 bilhões, cerca de US\$ 78,8 bilhões eram importações, ou 76,2\%. Vale destacar a expressiva elevação dos valores relativos à corrente de comércio interperíodos (exclusive 1989), que passou, como dito, de US\$ 18,0 bilhões para US\$ 103,5 bilhões, marcando um crescimento de $475,4 \%$. Fato este que torna explícita a maior articulação com o exterior, es- pecialmente a partir de: (a) 1993, no que tange ao déficit da balança comercial; e de (b) 1994, relativamente ao montante da corrente de comércio. Consente com a tendência anual de crescimento do déficit da balança comercial, o último ano da série, 2008, foi o de pior desempenho.

A evolução do índice da taxa de câmbio efetiva real e da taxa de câmbio real, no período 1988-2008, é apresentada na Figura 1. Pode-se notar, entre 2004 e 2008, uma forte tendência de valorização das taxas de câmbio (cujas variações são similares), o que pode ter contribuído para acentuar o peso das importações, relativamente às exportações, e, assim, para os seguidos déficits da balança comercial, uma vez que valorizações nas taxas de câmbio costumam implicar perda de competitividade da indústria nacional no comércio internacional. De fato, no período 20042008 as importações passaram de 5,8 para 12,7 bilhões de dólares. 
A Figura 1 apresenta, também, a evolução anual percentual da balança comercial da indústria farmacêutica que, aparentemente, acompanhou os movimentos do câmbio. Ou seja, a valorização das taxas de câmbio (que elevam o custo de oportunidade da produção local) foi acompanhada de uma elevação anual percentual das importações; especialmente no período 20022008. A partir de 2002, a variação percentual das importações passou a apresentar uma tendência de elevação, atingindo o seu maior patamar no ano de 2007.
As Figuras 2 e 3 apresentam a evolução do comércio exterior da indústria farmacêutica brasileira, no que tange, respectivamente, aos produtos farmacêuticos (capítulo 30 da NBM/ NCN) e aos produtos químicos orgânicos (capítulo 29 da NBM/NCM; em que estão incluídos os insumos para a fabricação de medicamentos). Comparativamente ao período I, o período II, no agregado (produtos farmacêuticos e químicos orgânicos), evidencia uma drástica ampliação da situação de dependência de produtos/insumos importados. Ao longo dos períodos I e II, pós-

Figura 1

Brasil: evolução da taxa de câmbio efetiva real * versus evolução anual percentual da Balança Comercial da Indústria Farmacêutica Brasileira **.

1a) Evolução da taxa de câmbio

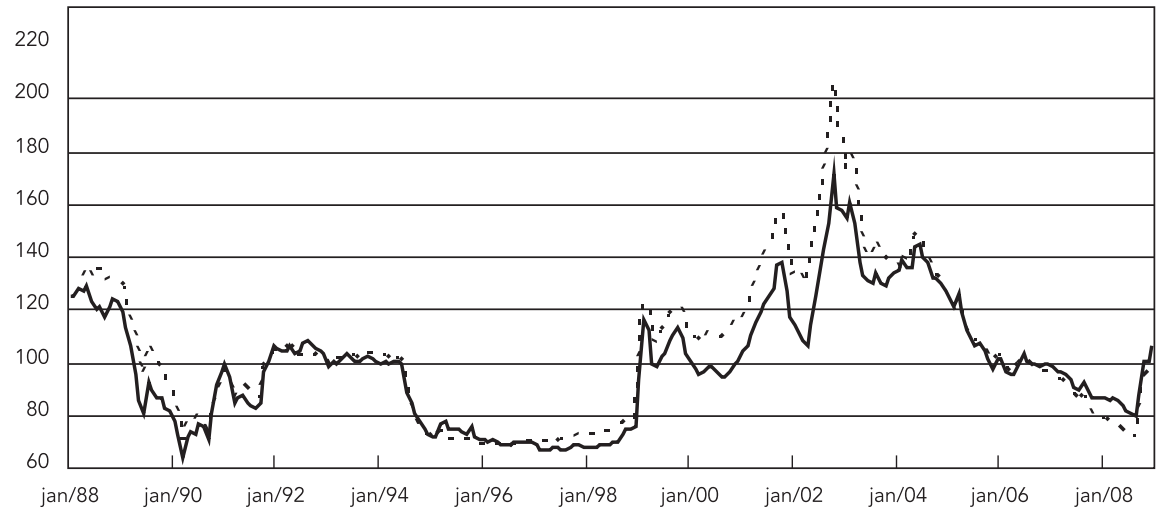

1752 - Índice da taxa de câmbio efetiva real (IPCA) - Jun $/ 1994=100$

11753 - Índice da taxa de câmbio real

(IPCA) - Jun/1994 = $100-$ Dólar americano

1b) Evolução anual \% da Balança Comercial

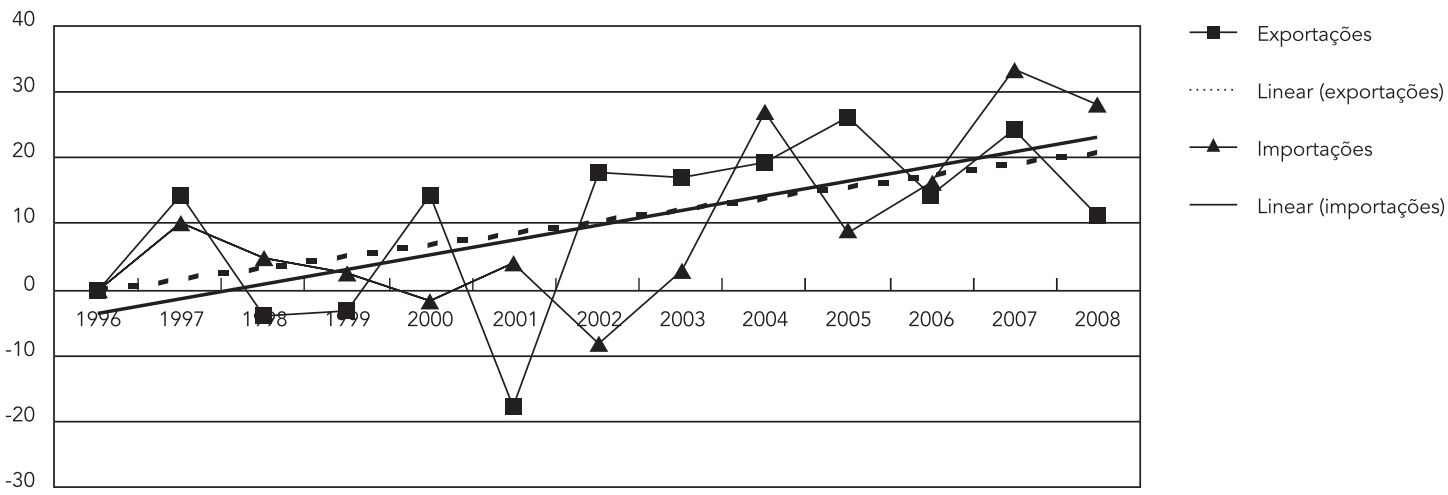

\footnotetext{
* Elaboração própria mediante os dados do Departamento Econômico, Banco Central do Brasil (junho de 1994 = 100 ; período 31 de dezembro de 1988 a 31 de dezembro de 2008);

** Elaboração própria mediante os dados do sistema ALICEweb (ano base 1996).
} 
liberalização comercial, o peso das importações esteve concentrado, maiormente, em insumos farmacêuticos (produtos químicos orgânicos). O fato novo, no entanto, é que especialmente a partir de 2004 se intensificou, e muito, o peso das importações de medicamentos - quando evoluiu de aproximadamente US\$ 1,8 bilhões, em 2004, para US\$ 4,3 bilhões em 2008, ou um crescimento de 139,8\%. Circunstância que marca, pois, o agravamento da dependência brasileira, também, de produtos acabados fabricados no exterior.

Segundo Gadelha 4, baseado na balança comercial do CEIS por produtos e blocos econômicos, ano 2004, a dependência de importações do Complexo se dá, majoritariamente, em produtos de maior conteúdo tecnológico (inclusive fármacos e medicamentos) provenien- tes de blocos de países desenvolvidos (Tratado Norte-Americano de Livre Comércio - NAFTA e União Europeia - UE), enquanto as exportações brasileiras, de menor conteúdo tecnológico, se destinam em grande parte aos blocos econômicos de países em desenvolvimento (Mercosul e resto do mundo). Se tal argumento é verdadeiro, então, a análise da balança comercial por países desenvolvidos, especialmente importação, e em desenvolvimento, exportação, pode apontar indícios de especialização regressiva no padrão de comércio internacional da indústria farmacêutica brasileira. A Figura 4 apresenta as informações. Observa-se, para os períodos I e II, que o saldo da balança comercial é deficitário nas transações com os dois grupos de países, desenvolvidos e em desenvolvimento. Entretanto, é marcadamente concentrado no primeiro grupo

Figura 2

Brasil: evolução do comércio exterior de produtos farmacêuticos - valores correntes US\$ free on board.

2a) Produtos farmacêuticos (1989-1995)

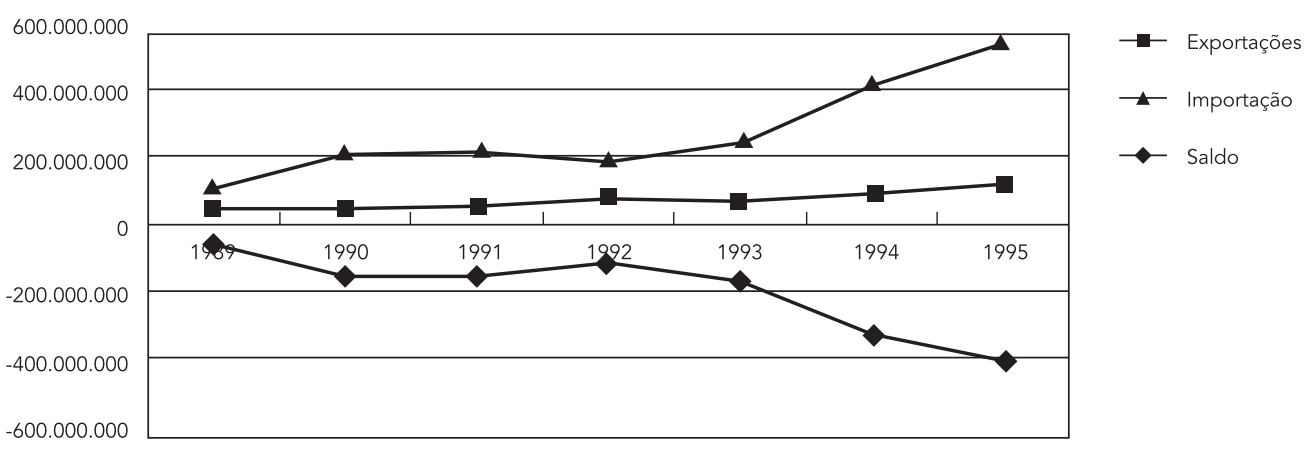

2b) Produtos farmacêuticos (1996-2008)

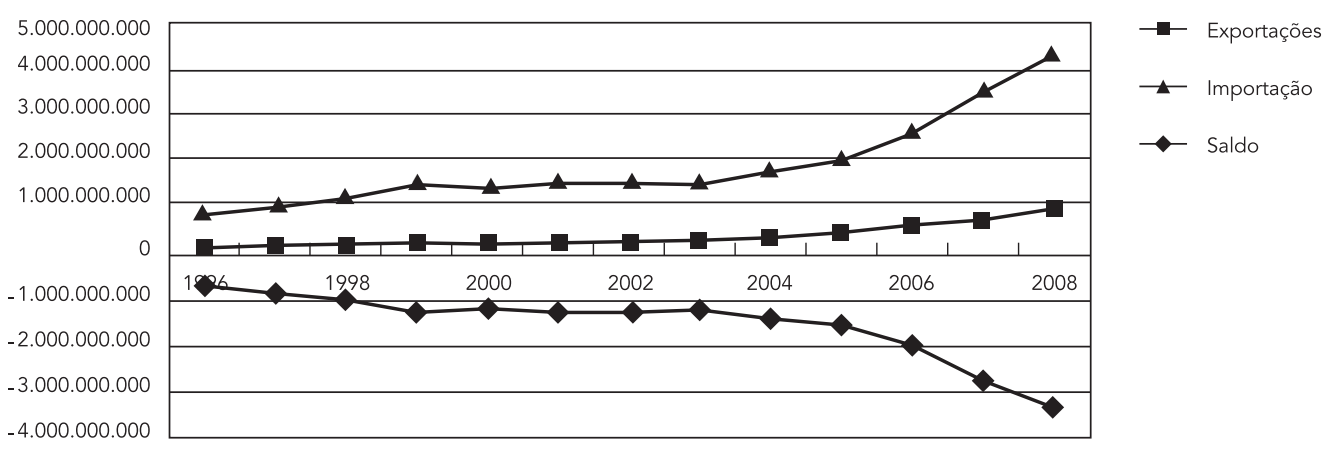

Fonte: elaboração própria mediante os dados do sistema ALICEweb. 
Figura 3

Brasil: evolução do comércio exterior de produtos químicos orgânicos - valores correntes US\$ free on board.

3a) Produtos químicos orgânicos (1989-1995)
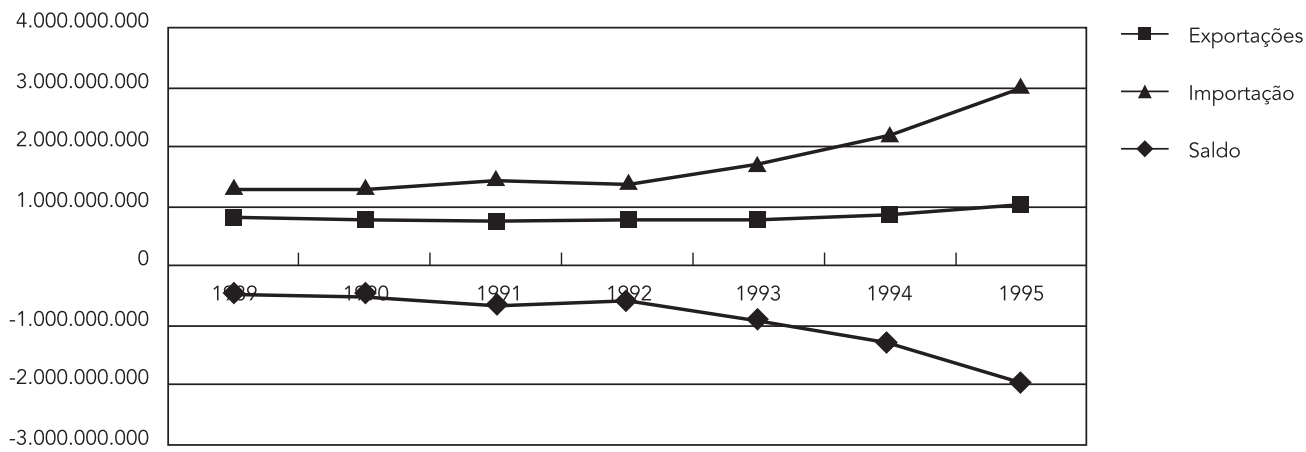

3b) Produtos químicos orgânicos (1996-2008)

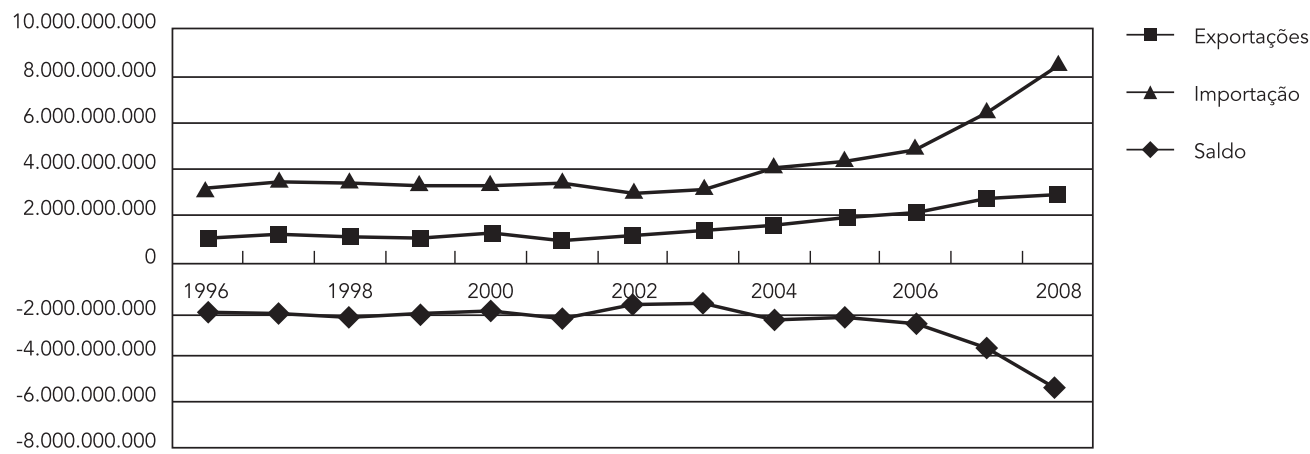

Fonte: elaboração própria mediante os dados do sistema ALICEweb.

de países, e, dentro dele, o maior peso se deu, como usual, nas importações de produtos químicos orgânicos.

Todavia, comparando-se os dois períodos ainda que os itens de produtos não sejam necessariamente os mesmos -, chama atenção a elevação acentuada do peso relativo dos produtos farmacêuticos na balança comercial brasileira. Entre 1996 e 2008, a importação de produtos farmacêuticos chegou a um montante de US\$ 20,9 bilhões, correspondendo a 33,4\% do total das importações (US\$ 62,5 bilhões); enquanto, entre 1989 e 1995, somou somente US\$ 1,5 bilhões, ou $14,2 \%$ do total das importações (US\$ 11,7 bilhões). Assim, para o grupo de países desenvolvidos, os dados evidenciam o crescimento do peso relativo da participação dos produtos farmacêuticos na pauta de importações - ainda que continue, majoritariamente, concentrada em produtos químicos orgânicos -, ratificando de certa forma o argumento - presente também em Gadelha 4 - de que o país passou a depender também de produtos acabados, fabricados no exterior. Por outro lado, as exportações brasileiras para ambos os grupos de países, quando comparado às importações, apresentam números bastante modestos; ainda que tenha evoluído acentuadamente após a abertura comercial dos anos 1990. Nos dois períodos, a maior parte das exportações de produtos farmacêuticos foi destinada a países em desenvolvimento, enquanto as exportações de químicos orgânicos ficaram mais concentradas nos países desenvolvidos. 
4a) Países desenvolvidos

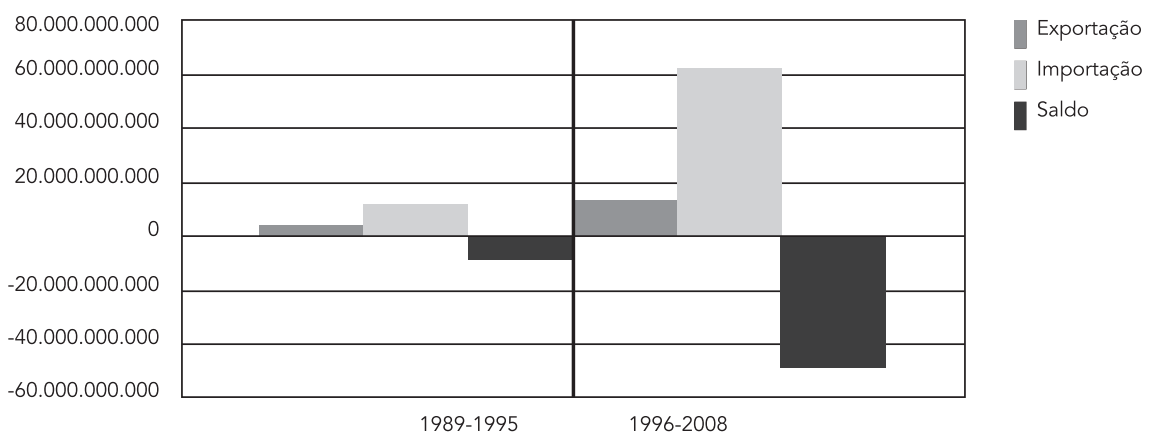

4b) Países em desenvolvimento

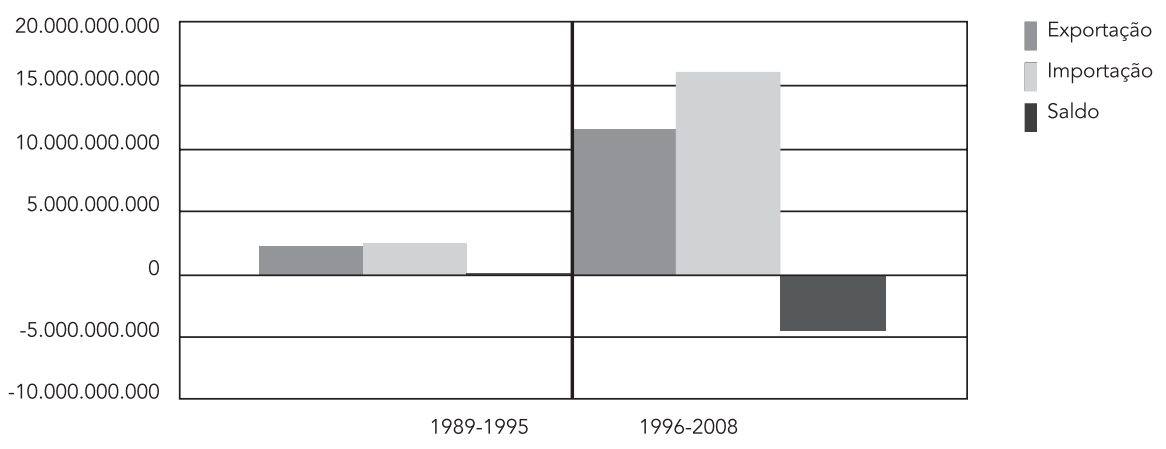

Fonte: elaboração própria mediante os dados do sistema ALICEweb.

\section{Considerações finais}

De modo geral, dado todo o exposto, o que se encontra é o agravamento da dependência externa do país em relação não apenas aos insumos farmacêuticos (produtos químicos orgânicos), mas também frente a produtos acabados fabricados no exterior (produtos farmacêuticos). Sendo tais produtos, como argumentado por Gadelha 4, intensivos em tecnologia e conhecimento, então, a elevação anual dos déficits comerciais, especialmente químicos orgânicos, pode sugerir a existência de especialização regressiva no padrão de comércio exterior da indústria farmacêutica brasileira. Ou seja, um deslocamento da produção local e dos esforços tecnológicos associados à sua fabricação, como função da maior articulação da indústria com o exterior após a liberalização comercial dos anos 1990 1,2. A confirmação de tal hipótese depende, contudo, da identificação dos itens de maior conteúdo tecnológico e sua dinâmica na pauta de exportações ao longo dos dois períodos estudados, mas especialmente pós 1996, não apenas pela mudança da NBM para a NCM, mas também porque se pode considerar ter havido tempo suficiente para a adaptação dos players às novas "regras do jogo"; inauguradas, como dito, com a abertura comercial a partir de 1990. 


\section{Resumo}

Em caráter exploratório, o objetivo deste artigo é investigar se há indicios de especialização regressiva no padrão de comércio exterior da indústria farmacêutica brasileira, a partir da liberalização comercial dos anos 1990. Para tanto, foi realizada uma análise estatística descritiva valendo-se de dados de comércio exterior de produtos farmacêuticos e químicos orgânicos, disponíveis no sistema ALICEweb, do Ministério do Desenvolvimento, Indústria e Comércio Exterior, abrangendo os períodos 1989-1995 e 1996-2008. Os resultados, sobretudo a evolução do padrão de comércio com países desenvolvidos, sugerem indícios de especialização regressiva.

Indústria Farmacêutica; Comercialização de Medicamentos; Comércio

\section{Colaboradores}

F. B. Mota contribuiu no planejamento do estudo, no método, levantou e analisou os dados e redigiu o artigo, bem como aprovou a versão a ser publicada. J. E. Cassiolato e C. A. G. Gadelha contribuíram no planejamento do estudo, método e revisão crítica do conteúdo do artigo, bem como aprovou a versão a ser publicada.

\section{Agradecimentos}

Os autores agradecem à colaboração dos Professores David Kupfer (Instituto de Economia, Universidade Federal do Rio de Janeiro), Hamilton Ferreira (Universidade Federal da Bahia) e Lúcio Freitas (Universidade Nove de Julho), pelos comentários e sugestões.

\section{Referências}

1. Katz, J. Regímenes sectoriales, productividad y competitividad internacional. Revista de la CEPAL 2001; (75):139-57.

2. Comisión Económica para América Latina y el Caribe. Regímenes competitivos sectoriales, productividad y competitividad internacional. Seminario sobre "Camino a la competitividad: El nivel meso y microeconómico". Santiago de Chile: Comisión Económica para América Latina y el Caribe; 2001.

3. Kupfer D. Política industrial. Revista Econômica 2004; 5:91-108.

4. Gadelha C. Desenvolvimento, complexo industrial da saúde e política industrial. Rev Saúde Pública 2006; 40(N Esp):11-23.

5. Ministério do Desenvolvimento, Indústria e Comércio Exterior. Comércio Exterior. Códigos e descrições - NCM. http://www.mdic.gov.br/ portalmdic/sitio/interna/interna.php?area= $5 \&$ menu $=1095 \&$ refr $=605$ (acessado em 09/Set/ 2009).

6. Secretaria de Comércio Exterior, Ministério do Desenvolvimento, Indústria e Comércio Exterior. Sistema de análise das informações de comércio exterior via Internet (ALICEweb). http://ali ceweb.desenvolvimento.gov.br/ (acessado em 09/ Set/2009).
7. Kupfer D. Trajetórias de reestruturação da indústria brasileira após a abertura e a estabilização [Tese de Doutorado] Rio de Janeiro: Universidade Federal do Rio de Janeiro; 1998.

8. Cimoli M, Katz J. Structural reforms, technological gaps and economic development: a Latin American perspective. Santiado de Chile: Comisión Económica para América Latina y el Caribe; 2006. (Serie Desarrollo Productivo, 129).

9. Katz J. Cambio estructural y capacidad tecnológica local. Revista de la CEPAL 2006; (89):59-73.

10. Ferraz J, Kupfer D, Iootty M. Competitividad industrial en Brasil 10 años después de la liberalización. Revista de la CEPAL 2004; (82):91-119.

11. Nassif A. Há evidências de desindustrialização no Brasil? Revista de Economia Política 2008; 28: 72-96.

Recebido em 12/Mar/2010

Versão final reapresentado em 23/Nov/2011

Aprovado em 23/Nov/2011 